\title{
INFLUENCE OF DEMOGRAPHIC PROCESSES ON ECONOMY OF A REGION
}

The paper presents two demographic models. The models are built for population of the Kirov region. The first one is a dynamic model. The second one applies the technique of ageing. By way of the correlationregression analysis significant factors influencing a birth and death rate factor are singled out. Both models forecast the dynamics of reduction of population in the region. An attempt is made to consider an influence of quality of life in the region on migratory processes. Economic problems concerned with depopulation are considered. Demographic changes affect all socio-economic spheres.

The problems of demography in the Kirov region are increasing. The population of the region is reduced. Since 1990 to 2009 the region population had decreased by 250.53 thousand people.

Migration decline occurs. In 2009 negative migration growth amounted to 3.8 thousand people.

Despite birth rate has recently been increased, death rate still exceeds birth rate; in 2005 death rate exceeded birth rate 2.04 times as much, and in 2008 - 1.51 times as much. In Russia upon the whole death rate exceeded birth rate 1.58 times in 2005, and in $2008-1.32$ times as much [1].

Research and prediction of demographic processes is required, so far as they have an influence on the labor market, consumer and service market, the market of savings is necessary. Change of the population size influences an investment climate, social expenditure, the system and size of taxation.

Let us consider demographic process simulation in the Kirov region.

In general, the equation of the population size is as follows:

$$
x_{t+1}=x_{t}\left(1-\beta_{t}\right)\left(1+r_{t}\right)+y_{t} .
$$

This equation takes into account the number of the dead, born and migration of the population: $x_{t}$ - population, $r_{t}$ - birth rate, $\beta_{t}-$ death rate, $y_{t}-$ migration growth for year $t$ (the difference between the entered and departed people).

Sampling of 15 medical and socio-economic indices was made. By way of the correlation-regression analysis interdependent indices were singled out.

As a result there are the followings socio-economic factors:

$x_{3}-$ proportion of university students per one inhabitant of the region; $x_{8}-$ gross regional product in thousands rubles per capita;

$x_{10}-$ expenses on public health services in rubles per capita;

$x_{12}$ - polluting emissions in kg per capita;

$x_{13}-$ consumption of alcoholic drinks in liters per capita.

Let us build a model of multiple linear regression for birth rate:

$$
\begin{aligned}
& \gamma=0,02-0,006 x_{3}+0,008 x_{8}+ \\
& +0,0003 x_{10}-0,003 x_{12}-0,007 x_{13} .
\end{aligned}
$$

Factors $x_{3}, x_{8}, x_{10}, x_{12}, x_{13}$ explain $64.51 \%$ of variability in the resultant criterion (birth rate) as $R^{2}=64.51$. Statistics $F=4.36$ is more than the tabular $F(6 ; 12)=4$ with the significance level $\alpha=0,05$. The regression equation is significant. Each regression factor is significant as $t_{\text {stat }}$ is more than $t_{c r}(12)=2.179$ and the $\mathrm{p}$-value is less than the significance level $\alpha=0,05$. Thus, the regression equation can be used for prediction.

The death rate is specified in a similar way. The selected significant factors, migration growth are specified on the basis statistical data by regression equations of time.

Migration growth y also is specified as linear regression of time.

All population of region is divided into three age groups: younger than the working age, working age and older than the working age. Each group is further divided by sex by residence in urban or rural areas.

The model is implemented at the object-oriented module of package Ithink 8.0. A size value of each age group at the initial stage is located at a separate chamber. Each chamber is represented as a two-dimensional array: lines - sex of a person, columns - region of residence. Chambers communicate with each other. At each step (each year) exchange between population groups takes place. Death rate and migration growth of each population group are considered. Different influence of factors is also considered.

The initial size values of the population groups have been taken for 1998 [2].

The results show that depopulation will occur at all the considered subgroups younger than the working age (Figure 1). However, since 2003-2004 certain growth of the population size is observed. So far as the diagrams are made by way of the Ithink 8.0 
1: мол т1уд[women,city] 2: мол т1уд[women,vill... 3: мол т1уд[men,city $\quad$ 4: мол т1уд[men,village $]$

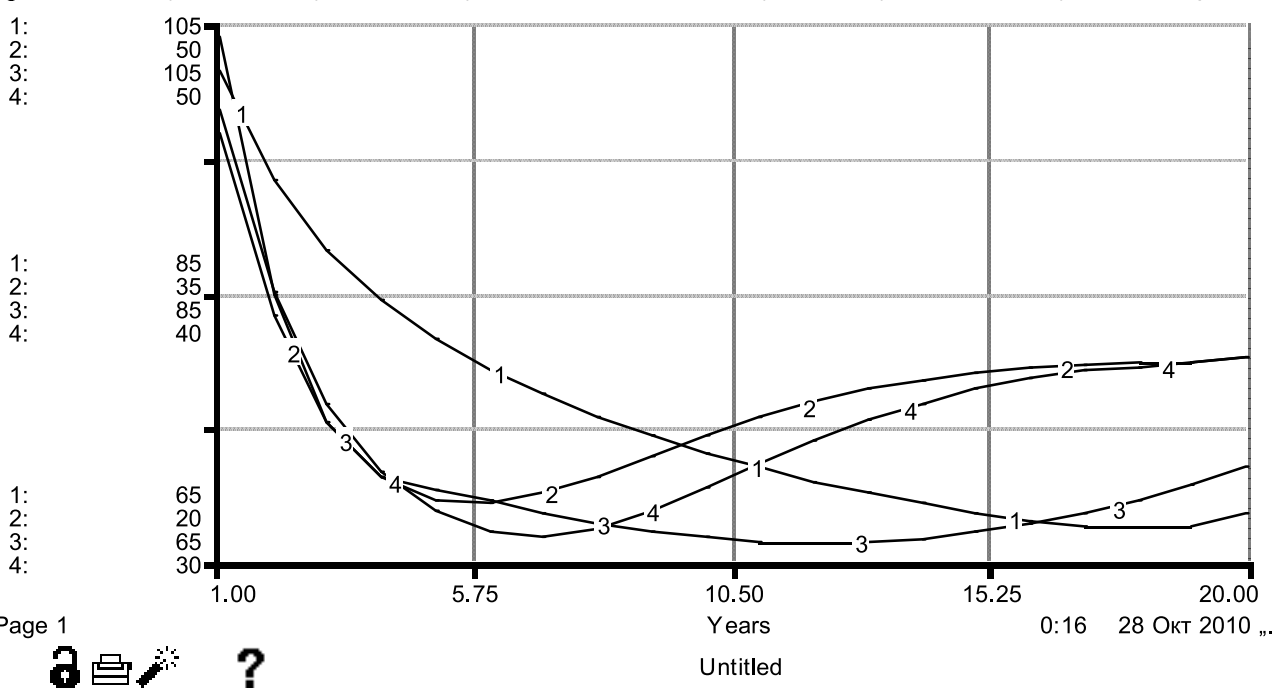

Fig. 1. Dynamics of the size of the group younger than the working age, thousand people

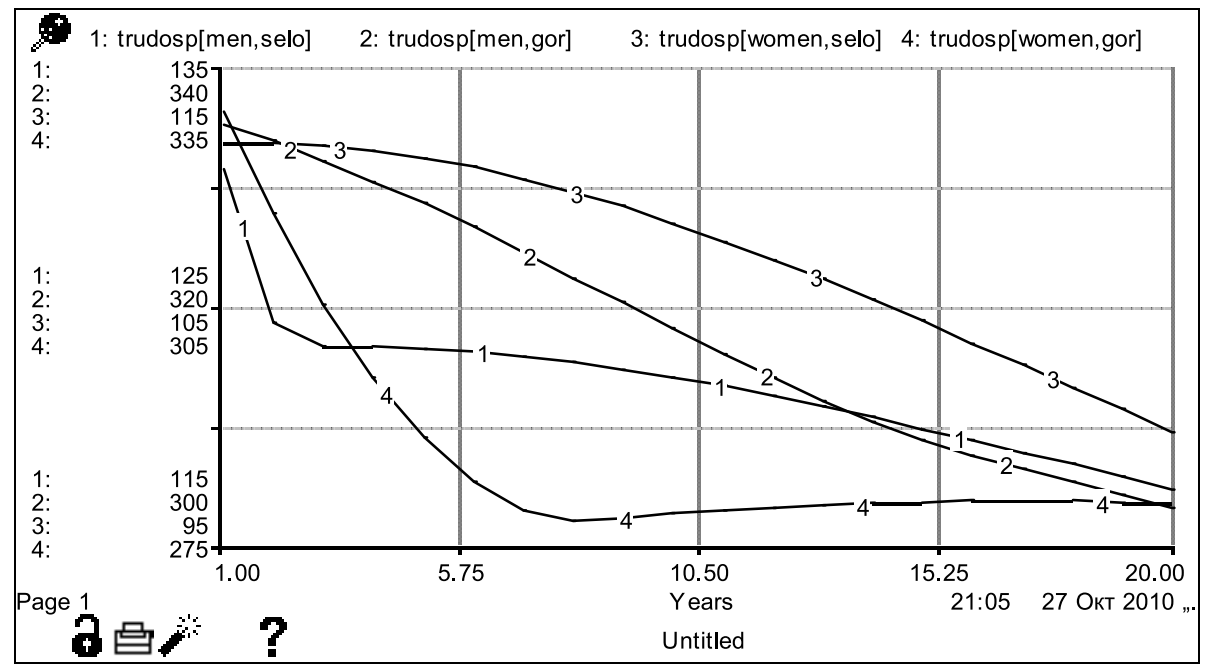

Fig. 2. Dynamics of the population size of the working age, thousand people

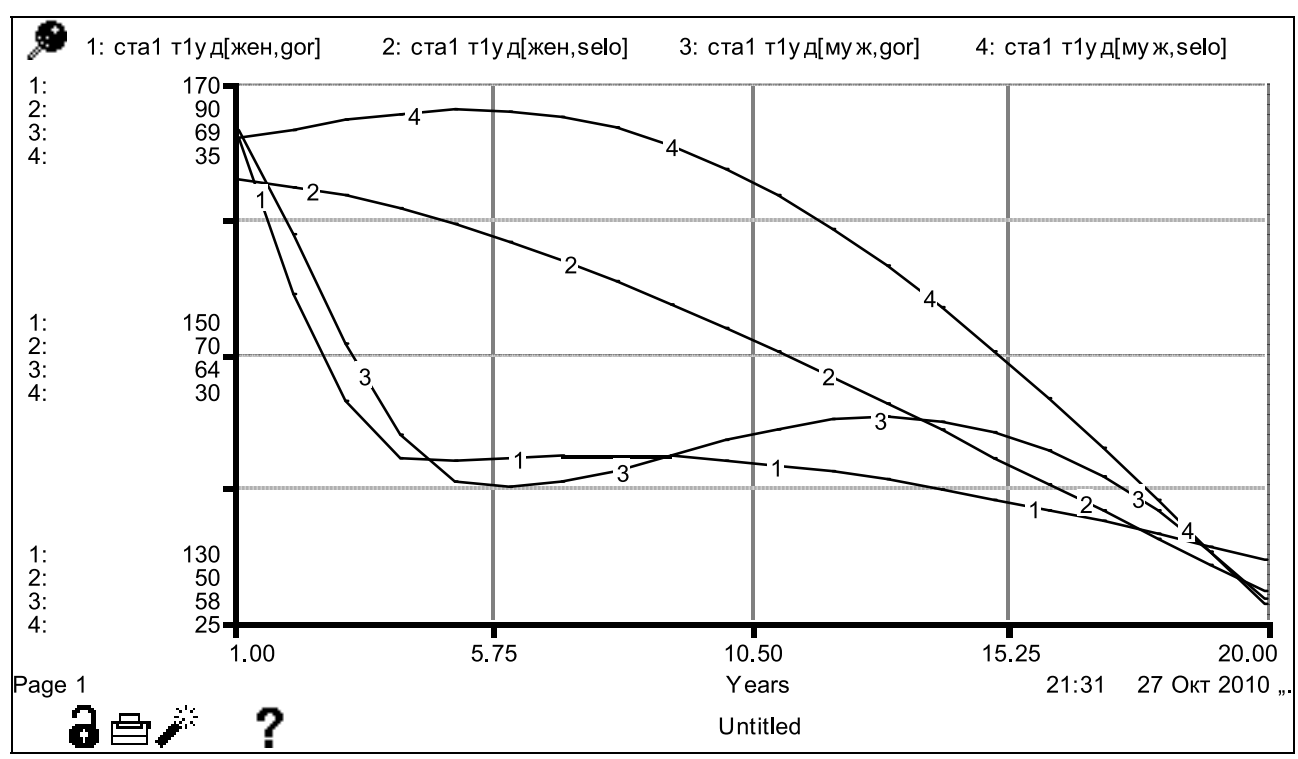

Fig. 3. Dynamics of the size of the older than the working age group, thousand persons 
program, then the program proper defines the ordinate scale for each age group. 1998 is taken as a unit at the axis of abscissas, and 2017 corresponds to 20 .

The number of men and women of the workingage in rural and urban areas decreases (Figure 2).

The increase at the subgroup of men older than the working age in rural areas stops approximately after 2000, which is proved by the statistics. At three other subgroups reduction of the population size (Figure 3) is observed. The rural population size das been decreased approximately by $37 \%$ on the average over 20 years, and by $20 \%$ - in urban areas.

Apart from the birth and death rate, the population size dynamics is influenced by migration growth. Migration growth in the Kirov region is negative.

According to statistical data referred to migration growth in the Kirov region, it is possible to single out 3 Federal Districts with the highest migration rate in the region: the Central, North-Western and Volga Districts. To build a model, socio-economic indices for the Kirov region (K), the Nizhny Novgorod region $(\mathrm{N})$, the Perm Territory $(\mathrm{P})$ and the Moscow (M) and St. Petersburg (SP) regions of 1996 to 2008 were applied.

Out of all the indices according to which a level and quality of life are estimated, the following were selected:

1) gross regional product per capita, vrp;

2) subsistence level rate or minimum consumer goods basket, mpk;

3) unemployment rate, bezr;

4) average total area of living space per inhabitant, metr.

For each region a coefficient is calculated as an expression:

$$
k_{i}=\frac{v r p \cdot m e t r}{b e z r \cdot m p k} .
$$

Then, the ratio is built:

$$
k_{i_{-} K}=\frac{k_{i}}{k_{K}},
$$

where $i \in\{K, M, P, N, S P\}, k_{K}-$ coefficient for the Kirov region.

Migration with the quality of life taken into account, is specified:

$$
\begin{aligned}
k \_ \text {migr } & =\text { migr }\left(1-\frac{k_{M_{-} K}}{k_{M_{-} \max }}\right)\left(1-\frac{k_{P_{-} K}}{k_{P_{-} \max }}\right) \times \\
& \times\left(1-\frac{k_{N_{-} K}}{k_{N_{-} \max }}\right)\left(1-\frac{k_{S_{P_{-} K}}}{k_{S P_{-} \max }}\right)
\end{aligned}
$$

Expressions for migr, vrp, metr, bezr, mpk are specified as regression of time.
Modeling of migration with account for the quality of life allows obtaining more precise results on the demographic indicators.

Let us consider another method of prediction of the population size in the region. It is the technique of ageing. To use the given technique, it is necessary to know an average number of people of a particular age interval. Such values are taken from mortality tables.

Let us consider ageing for five-year groups. The given mortality tables allow calculating survival coefficients.

$$
\begin{gathered}
P_{x / x+4}=\frac{L_{x+5 / x+9}}{L_{x / x+4}}= \\
=\frac{L_{x+5}+L_{x+6}+L_{x+7}+L_{x+8}+L_{x+9}}{L_{x}+L_{x+1}+L_{x+2}+L_{x+3}+L_{x+4}},
\end{gathered}
$$

where $L_{x}-$ the average number of people aged from $x$ to $x+1$.

Ageing is carried out by time steps equal to the length of the age group (5 years), so that the survived population of the age group passed to the next (older) age interval with each prediction step. So far as the step is equal to 5 , then the population size in five years will be equal to:

$$
S_{x+5}=S_{x} P_{x / x+4}
$$

$S_{x}$ - population size of $x$ years of age at the beginning of the reporting period.

Taking into account the migration growth, the formula (6) will be written down as:

$$
S_{x+5}^{\prime}=S_{x+5}\left(1+\beta^{\Delta}\right) P_{x / x+4},
$$

where $S_{x+5}^{\prime}-$ expected population size of $x+5$ years of age with account for migration;

$S_{x+5}$ - expected population size of $x+5$ years of age according to the results of ageing without migration taken into account;

$P_{x / x+4}-$ coefficient of survival taken into account while ageing and calculated according to the mortality tables' data;

$\beta^{\Delta}-$ migration growth [3].

Let us test the simulation model and the technique of ageing (Table).

Let us calculate ratio error for each method. For the technique of ageing an average error is approximately $13 \%$, for the dynamic model - approximately $17 \%$. Thus, the technique of ageing is more exact, than the dynamic model.

Both models predict percentage growth of the older than working age group in an aggregate population size. 


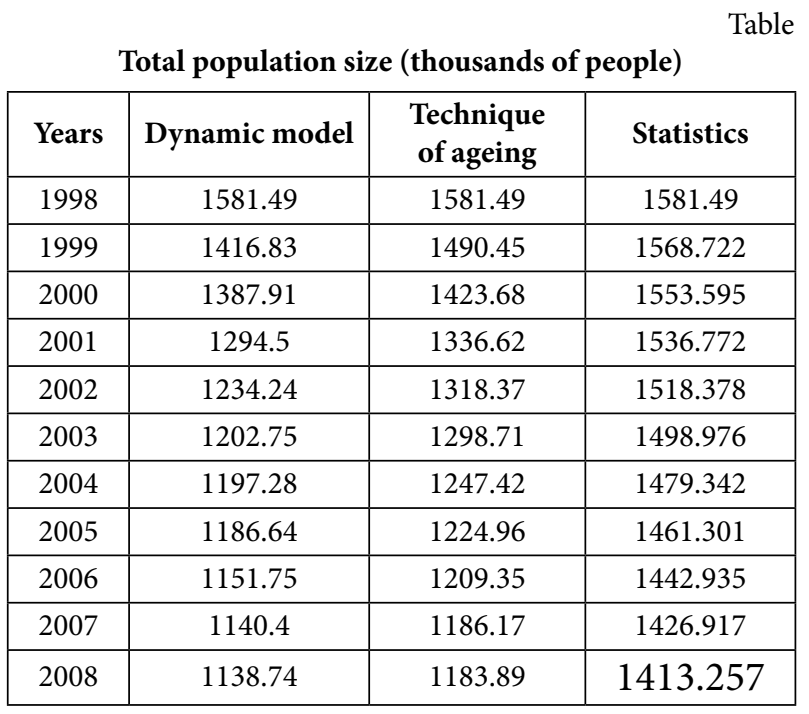

The increase in the number of the retirement age people leads to economic problems, increases loading on people of the working age. Besides, fast ageing of the population occurs, i. e. increase in a number of senior-age people, and, accordingly, growth of the average age of potential workers.

In the Kirov region in 1979 a number of the younger group of the working-age population (16-29 years of age) was 1.6 times larger in number than the senior group, and in 2008 only 1.1 times. According to the model predictions, the ratio will be 1.04 by 2018 .

Besides, high death rate reduces the working time fund. In addition, not all the working-age population is economically active. Boundary ages of 16-24 years of age and the pre-retirement age (Figure 4) are rather inactive. Representatives of the young group mostly study at higher educational institutions, and representatives of the senior group, as a rule, have already poor health.

So far as the share of the senior age groups in the manpower structure will increase both across Russia, and in the Kirov region, the cumulative working time fund available for the economy will be reduced even more than the number of potential workers [4].

The technique of ageing also confirms reduction of the regional population size.

Thus, the analysis of demographic situation prediction showed that the Kirov region experiences an

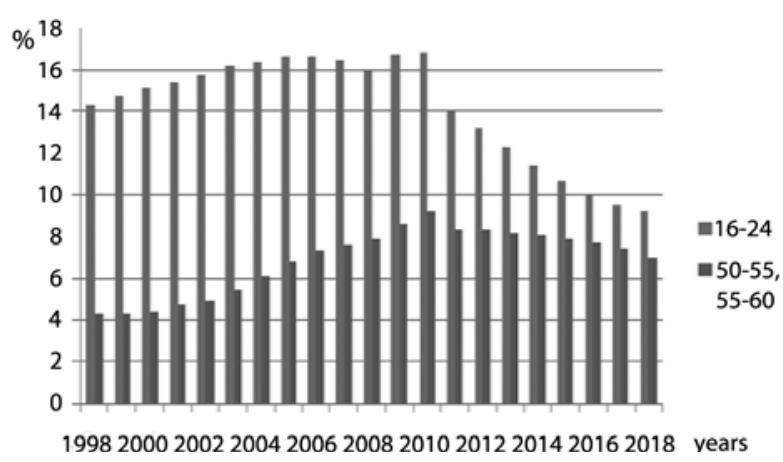

Fig. 4. Size of the group of 16-24 years of age and the preretirement age in percentage in an aggregate population size of the Kirov region

acute demographic problem, which will continue to develop in the future.

Key factors influencing birth and death rate have been exposed. The administration and social services should consider the given factors.

Not only birth rate is to be increased and death rate to be reduced, but the problem of migration loss is to be solved at the administrative regional level.

A primary task for the Kirov region is to stop the outflow of the working-age population. It has been shown that it is one of the main reasons of reduction of the regional population size.

To solve the problem of migration loss, it is necessary to create favorable living conditions, first of all, affordable housing, workplaces providing worthy wages, i.e. to enhance the quality of people's life.

\section{References}

1. The Kirov region in figures.2009. Federal State Statistics Service in the Kirov region. Retrieved from: www.kirovstat.kirov.rugks.ru

2. Russia in figures. 2009. Federal State Statistics Service. Retrieved from: www.gks.ru

3. Harchenko, L. P. (2009). Demography: teaching aid. Moscow: Omega-L. 350 p.

4. Reduction and ageing of manpower is adverse for the labor market. Retrieved from: http://www.polit.ru/research/2010/08/24/demoscope429.html

\section{U.D.C. 519.7}

keywords: population, mortality, fertility, migration growth, dynamic model, quality of life, the technique of ageing 